\title{
Monitoring of non-progressive retinoschisis detachment with posterior outer leaf break
}

\author{
Hafiz Muhammad Ejaz-Ul-Haq, ${ }^{1}$ Syed Bilal Hassan Zaidi, ${ }^{2}$ Kirk A J Stephenson (D) , \\ Zubair Idrees ${ }^{3}$
}

'Ophthalmology, Broomfield Hospital, Chelmsford, UK ${ }^{2}$ Ophthalmology, Mater Misericordiae University Hospital, Dublin, Ireland ${ }^{3}$ Ophthalmology, Cork University Hospital, Cork, Ireland

Correspondence to Dr Kirk A J Stephenson; kirkstephenson@hotmail.com

Accepted 8 March 2021

\section{DESCRIPTION}

A 30-year-old emmetropic man presented with a 1-day history of left eye nasal shadow, without flashes, floaters or decreased vision. He had no relevant medical, ophthalmic or family history. Visual acuity was $6 / 6$ bilaterally, with normal pupillary reactions and intraocular pressures. There was left inferotemporal retinoschisis (RS) detachment (RSD) extending to the inferior macular arcade with a posterior outer leaf break without posterior vitreous detachment (PVD) (figure 1). There was a small contralateral inferotemporal RS. Optical coherence tomography (OCT) of the RSD revealed a large outer leaf break with subretinal fluid (SRF) extension (figure 2A). Without treatment, RSD was non-progressive during the 6-month follow-up (figure 2B).

RS is a splitting of the neurosensory retina (NSR) into two layers with interface fluid. Juvenile $\mathrm{RS}$ is X-linked, affecting young males (incidence 1:15000-30 000) due to mutated intercellular adhesion proteins (retinoschisin). ${ }^{12}$ Senile RS is degenerative, more common (3.9\%-38\%), and typically inferotemporal in older adults of either gender, though younger exceptions apply. ${ }^{3}{ }^{4}$ Both forms may be bilateral and typically associated with hyperopia; however, senile RS can be seen with low myopia. Anatomically, RS has two subtypes: (1) flat RS (57\%), being anterior to the equator without retinal breaks and (2) bullous-RS (43\%), commonly posterior to the equator, associated with outer leaf breaks. ${ }^{5}$ OCT facilitates diagnosis, determines extent and demarcates inner leaf/outer leaf breaks in $\mathrm{RS}^{4}{ }^{4} \mathrm{RS}$ rarely threatens vision, and must be

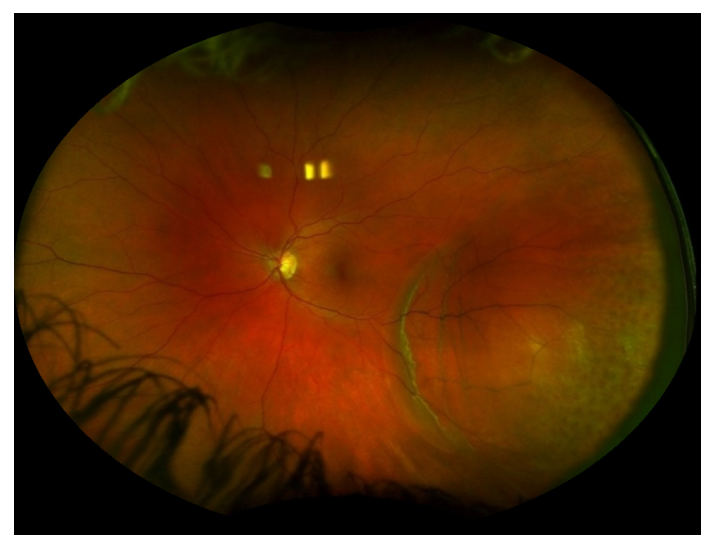

Figure 1 Colour fundus photograph (Optos, Scotland) of the left eye showing inferotemporal retinoschisis detachment. Of note is the dome-shaped contour with clear demarcation at the posterior extent.

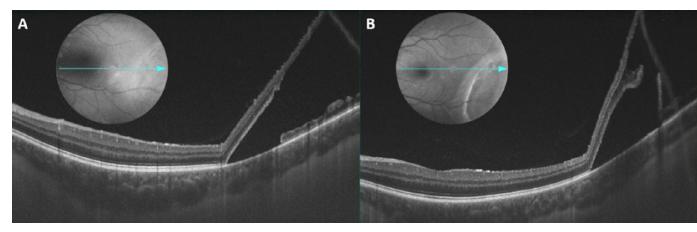

Figure 2 (A) Optical coherence tomography (OCT; Topcon Corporation, Tokyo, Japan) of the retinoschisis detachment area showing break in the outer leaf of retinoschisis resulting in some extension of fluid into the subretinal space resulting in retinoschisis detachment. (B) Follow-up OCT 6 months after presentation showing no posterior progression in the extent of retinoschisis detachment. The circular inlay images show the plane of the OCT line scan. NB: Neither inner leaf breaks nor posterior vitreous detachment were seen clinically or on OCT.

distinguished from rhegmatogenous retinal detachment (RRD) due to breaks in both leaves of a RS..$^{5-7}$ If fluid from an RS cavity enters the subretinal space via an outer leaf break, this is known as a RSD, which rarely extends beyond the RS margins due to the viscous nature of mucopolysaccharide-rich RS cavity fluid. ${ }^{489}$ RSD is easily overlooked; however, lack of uniformity and apparent heterogeneity of retinal density/transparency due to compartmentalised SRF may aid detection. ${ }^{6}$

Though subjective visual field may help differentiate RS from RRD, OCT is an objective tool for accurate assessment of NSR position relative to the retinal pigment epithelium. ${ }^{4} \mathrm{RS}$ is not typically associated with flashes and floaters, which may be due to unrelated PVD with coincidental diagnosis of a pre-existing $\mathrm{RS}^{6}{ }^{6}$ though subsequent PVD may destabilise RS/RSD to RRD. Outer leaf breaks (24\% of RS) are more important than inner leaf breaks as they may lead to RSD (56\%$60 \%$ of RS) or RRD $\left(0.05 \%\right.$ of RS). ${ }^{6}$ RSD rarely extends into the macula, at which stage, surgical intervention is warranted. $^{78}$ A long-term study of untreated asymptomatic RSD eyes (6.3-year follow-up, $\mathrm{n}=13$ ) showed stability in $85 \%$ with regression in the remainder, suggesting observation as safe first-line management. ${ }^{68}$ Treatment options include cryotherapy, photocoagulation, scleral buckling \pm SRF drainage, and vitrectomy \pm gas/ oil tamponade \pm schisis deroofing or retinotomy; however, these interventions may be complicated by RRD, maculopathy, vitreous haemorrhage, new retinal breaks and proliferative vitreoretinopathy. ${ }^{6}{ }^{10}$ Considering the typically non-progressive behaviour of RSD and the visually significant risks 
of treatment, observation is first-line management with intervention reserved for cases in which RSD progression endangers the macula.

\section{Learning points}

- Acquired retinoschisis (RS) prevalence is 3.9\%-38\% in adults, typically in hyperopes, and may be complicated by localised RS detachment (RSD) if outer leaf breaks are present $(56 \%-$ $60 \%$ ) or progressive rhegmatogenous retinal detachment (RRD) $(0.05 \%)$ if inner leaf and outer leaf breaks are present.

- RS is translucent, inflexible (ie, does not flatten with scleral depression), smooth, well-demarcated and causes an absolute scotoma while RRD is irregular, opaque, flattens with scleral depression (with the exception of bullous RRD) 46 and gives rise to a relative scotoma.

- RSD is a rare complication of RS and is very slowly progressive or non-progressive due to viscous schisis fluid modified by the presence or absence of posterior vitreous detachment and both inner and outer leaf breaks. First-line management is close observation with invasive treatment (eg, vitrectomy, scleral buckle, laser or cryotherapy) reserved for progressive cases, which endanger the macula.

Acknowledgements The photographic department of Cork University Hospital Eye Clinic.

Contributors HMEUH: Patient care, manuscript drafting and revision. SBHZ: Manuscript drafting and revision. KAJS: Manuscript drafting and revision. ZI: Patient care, manuscript drafting and revision.
Funding The authors have not declared a specific grant for this research from any funding agency in the public, commercial or not-for-profit sectors.

Competing interests None declared.

Patient consent for publication Obtained.

Provenance and peer review Not commissioned; externally peer-reviewed.

\section{ORCID iD}

Kirk A J Stephenson http://orcid.org/0000-0002-7462-7725

\section{REFERENCES}

1 Kellogg Eye Center. Retinoschisis, 2020. Available: https://www.umkelloggeye.org/ conditions-treatments/retinoschisis

2 Stephenson K, Dockery A, Wynne N, et al. Multimodal imaging in a pedigree of Xlinked retinoschisis with a novel RS1 variant. BMC Med Genet 2018;19:195.

3 Alberts M, Sutter J, Payne K. Retinoschisis: a teaching case report. J Assoc Sch Coll Optomet 2018;43.

4 Ho VY, Wehmeier JM, Shah GK. Wide-Field infrared imaging: a descriptive review of characteristics of retinoschisis, retinal detachment, and schisis detachments. Retina 2016;36:1439-45.

5 Straatsma BR, Foss RY. Typical and reticular degenerative retinoschisis. Am J Ophthalmol 1973;75:551-75.

6 Byer NE. Long-term natural history study of senile retinoschisis with implications for management. Ophthalmology 1986;93:1127-37.

7 Reed D, Gupta O, Garg S. Managing complications of retinoschisis. Retina Today 2014:32-9.

8 Byer NE. Perspectives on the management of the complications of senile retinoschisis. Eye 2002;16:359-64.

9 Byer NE. Retinoschisis. In: Regillo C, Brown G, Flynn H, eds. Vitreoretinal disease: the essentials. New York: Thieme, 1998

10 Xue K, Muqit MMK, Ezra E, et al. Incidence, mechanism and outcomes of schisis retinal detachments revealed through a prospective population-based study. $\mathrm{Br} J$ Ophthalmol 2017;101:1022-6.

Copyright 2021 BMJ Publishing Group. All rights reserved. For permission to reuse any of this content visit

https://www.bmj.com/company/products-services/rights-and-licensing/permissions/

BMJ Case Report Fellows may re-use this article for personal use and teaching without any further permission.

Become a Fellow of BMJ Case Reports today and you can:

- Submit as many cases as you like

- Enjoy fast sympathetic peer review and rapid publication of accepted articles

- Access all the published articles

- Re-use any of the published material for personal use and teaching without further permission

Customer Service

If you have any further queries about your subscription, please contact our customer services team on +44 (0) 2071111105 or via email at support@bmj.com.

Visit casereports.bmj.com for more articles like this and to become a Fellow 